\title{
Atividades de trabalho e os distúrbios osteomusculares de trabalhadores em uma instituição de idosos
}

\author{
Janaína Bussola Montrezor, Maria do Carmo Baracho de Alencar
}

\begin{abstract}
Resumo: Objetiva-se investigar os aspectos de risco para distúrbios osteomusculares de profissionais de enfermagem que cuidavam/assistiam idosos em uma instituição asilar na cidade de Santos-SP. Os materiais e métodos consistiram de elaboração e aplicação de instrumental sob forma de entrevista junto aos trabalhadores, contendo dados demográficos gerais e questões relacionadas ao trabalho, além do Questionário Nórdico de Sintomas Osteomusculares-QNSO (PINHEIRO; TRÓCCOLI; CARVEL, 2002), com questões adicionais. Aplicou-se também o Índice de Barthel (MAHONEY; BARTHEL, 1965) junto aos idosos diretamente cuidados/assistidos pelos trabalhadores $(\mathrm{n}=40)$, para se verificarem as possíveis sobrecargas físicas. Posteriormente, realizou-se, junto aos trabalhadores com sintomas osteomusculares nos 30 dias anteriores à entrevista, o levantamento de tarefas e observações sistemáticas de atividades de trabalho com base na Ergonomia (GUÉRIN et al., 1997), sendo selecionadas para as observações as transferências e deslocamentos dos idosos, e o banho e a troca de fraldas. Um total de oito $(n=08)$ trabalhadores participaram do estudo ( 07 do gênero feminino e 01 do gênero masculino), com idade entre 30 e 58 anos. A região mais acometida pelos trabalhadores foi a lombar. Os resultados indicaram alguns aspectos de risco para os distúrbios osteomusculares, como: altura das camas, condições das cadeiras de rodas e distância dos trajetos em deslocamentos, entre outros; outros aspectos estavam aliados aos níveis de capacidade funcional e peso dos idosos; observaram-se também aspectos relacionados à organização do trabalho, como: repetitividade de movimentos e posturas de risco, ritmo de trabalho acelerado, número insuficiente de trabalhadores, problemas relacionados à divisão das tarefas, entre outros. Concluiu-se que aspectos relacionados às condições e à organização do trabalho influenciaram nos distúrbios osteomusculares, sendo aspectos importantes a serem analisados para a prevenção.
\end{abstract}

Palavras-chave: Condições de Trabalho, Instituição Asilar, Distúrbios Osteomusculares, Ergonomia, Terapia Ocupacional.

\section{Working activities and workers' musculoskeletal disorders in a shelter for the elderly}

\begin{abstract}
The purpose of this study was to investigate the risk aspects of musculoskeletal disorders among nursing professionals who assisted the in a nursing home in Santos, State of Sao Paulo. Materials and methods consisted of preparing and applying the instruments next to the workers, such as an interview containing general demographic data, work related issues, and the Nordic Musculoskeletal Questionnaire - QNSO (PINHEIRO et al., 2002), with additional questions. Also, the instrument Barthel Index (Mahoney and Barthel, 1965) was applied next to the elderly assisted directly by the workers $(n=40)$ to verify the possible physical efforts. After that, it was applied the survey of tasks and systematic observations of the working activities based on Ergonomics (GUÉRIN et al., 1997); transfers and displacements of the elderly, bathing, and diaper changing were the activities selected among workers who presented musculoskeletal symptoms in the past 30 days. A total of eight $(n=08)$ workers participated in the study ( 07 women and 01 men), aged between 30 and 58. The lumbar region was the most affected among workers. The results indicated some risk aspects to musculoskeletal disorders: bed height, wheelchair conditions, distance of paths in transfers, among others; associated with the functional capacity level and weight of the elderly,as well as to work organization aspects such as repetitiveness of risk movements and posture, accelerated rhythm, insufficient number of workers, issues related to the sharing of tasks, etc. It was concluded that the working conditions and organization had an influence on the musculoskeletal disorders, and are important aspects to be analyzed for prevention.
\end{abstract}

Keywords: Working conditions, Homes for the Aged, Musculoskeletal Disorders, Ergonomics, Occupational Therapy.

Autor para correspondência: Maria do Carmo Baracho de Alencar, Av. Saldanha da Gama, 89, CEP 11030-400, Santos, SP, Brasil, e-mail: belinha.alencar1@gmail.com

Recebido em 26/11/2010; $1^{\text {a }}$ Revisão em 23/7/2011; 2 $2^{\text {a }}$ Revisão em 13/8/2011; Aceito em 19/9/2011. 


\section{Introdução}

O mundo do trabalho tem sofrido intensas transformaçôes nos últimos anos com a introdução de novas tecnologias, a aceleração do ritmo de trabalho, as mudanças nos processos e modos de organização do trabalho e a globalização, entre outras, que vêm afetando a saúde dos trabalhadores tanto no aspecto físico quanto mental (LANCMAN, 2004). Uma das formas de adoecimento relacionado ao trabalho contemporâneo são as Lesóes por Esforços Repetitivos (LER) ou Distúrbios Osteomusculares Relacionados ao Trabalho (DORT). Os distúrbios osteomusculares relacionados ao trabalho (DORT) vêm assumindo um caráter epidêmico em vários países do mundo e em diversas categorias profissionais, representando um dos principais grupos de agravos à saúde entre as doenças ocupacionais em nosso país (BRASIL, 2001).

Para Punnet e Wegman (2004), os DORTs incluem uma variedade de condições inflamatórias e degenerativas que afetam os músculos, tendóes, ligamentos, articulações, nervos periféricos, etc. Segundo o Brasil (2001), os sinais e sintomas são diversificados, sendo os principais: dores espontâneas ou à movimentação passiva, ativa ou contra resistida, e alteraçóes sensitivas de fraqueza, cansaço, peso, dormência, entre outras, de aparecimento insidioso. Os distúrbios osteomusculares relacionados ao trabalho são multifatoriais, envolvendo fatores físicos, organizacionais e psicossociais, além de aspectos individuais e socioculturais (CHIAVEGATO FILHO; PEREIRA JUNIOR, 2004). Para Brasil (2006), os DORTs têm relação direta com as exigências das tarefas e com os ambientes nos quais esses trabalhos são desenvolvidos.

Entre os trabalhadores que cuidam/assistem idosos em Instituições Asilares, estáo os profissionais da área da Enfermagem. Vários estudos apontam a presença de distúrbios osteomusculares em trabalhadores dessa categoria profissional (MUROFUSE; MARZIALE, 2005; GURGUEIRA; ALEXANDRE; CORREA FILHO, 2003). Alexandre (1998) aponta como fatores de risco para os DORTs entre os trabalhadores de Enfermagem: o transporte e a movimentação de pacientes, a manutenção de posturas inadequadas e estáticas, os movimentos frequentes de flexão e torção da coluna vertebral, e os fatores ergonômicos inadequados de mobiliários e equipamentos utilizados nas atividades cotidianas relativas ao trabalho. Para Zanon e Marziale (2000), em estudo com profissionais de Enfermagem, foram apontados aspectos de dificuldades no trabalho e riscos para os DORTs, como: pouco espaço para o trabalho $(58,82 \%)$, carga física elevada $(52,94 \%)$ e falta de pessoal para as exigências do trabalho (47,06\%), sendo obtido dos trabalhadores mais de um relato dessas dificuldades.

Gurgueira, Alexandre e Correa Filho (2003) citam que as regiōes dolorosas mais atingidas por trabalhadores de enfermagem foram: região lombar, ombros, cervical e joelhos. Para Parada, Alexandre e Benatti (2002), as lesóes ocupacionais de atendentes de Enfermagem foram mais comuns na região lombar e com maior frequência, sendo que estas ocorreram durante a manipulação de equipamentos e com pacientes obesos e dependentes.

Entre os modelos teóricos que estudam saúde e o trabalho, está a Ergonomia, uma disciplina orientada aos sistemas, estendendo-se por todos os aspectos da atividade humana, visando promover uma abordagem holística do trabalho, na qual consideraçóes de ordem física, cognitiva, social, organizacional, ambiental e de outros aspectos relevantes, devem ser levadas em conta (FALZON, 2007).

A Ergonomia de origem européia considera a análise global das situaçóes de trabalho, visando melhorá-lo. Para Daniellou (2004), a análise da atividade de trabalho avalia os comportamentos, condutas e processos cognitivos, bem como as interações existentes durante as observaçóes que são feitas no trabalho. De acordo com Guérin et al. (1997), a análise da atividade de trabalho estuda a situação visando adaptá-la ao homem a partir da análise das condiçōes técnicas, ambientais e organizacionais.

O trabalho implica em tarefa e atividade. A tarefa constitui-se no que é prescrito para ser feito e a atividade no que é efetivamente realizado pelo trabalhador ao executar a tarefa. Dejours (2005) cita que a atividade real contém reajustes dos modos operacionais na tentativa de se aproximar das exigências impostas pela tarefa. Assim, tanto o trabalho prescrito como a atividade real veiculam de maneira implícita um "custo" humano do trabalho, que é abordado em Ergonomia em termos de carga de trabalho. O conceito de carga de trabalho é marcado por controvérsias, ambiguidade e imprecisão. De um modo geral, a noção de carga de trabalho aparece associada às duas dimensóes: as exigências externas, presentes na situação de trabalho, e os efeitos percebidos pelos trabalhadores em relaçáo a essas exigências externas; seria a compreensão das inter-relaçôes trabalho-desgaste vivenciada pelo trabalhador (BRITO, 1991). Nesse sentido, a carga de trabalho não é determinada apenas por aspectos físicos do trabalho. A saúde do trabalhador pode ser afetada tanto por aspectos relacionados às condiçóes de trabalho quanto pelos aspectos da organização do 
trabalho. As relaçóes de trabalho evidenciadas pela grande competitividade e pelos níveis de exigência e produtividade são fatores que, consequentemente, promovem alteraçôes no processo saúde-doença da humanidade (LEITE; SILVA; MERIGHI, 2007).

Dejours (1992) considera como condiçôes de trabalho os ambientes físicos (temperatura, pressão, etc), químicos (fumaças, gases tóxicos, etc), biológicos (vírus, fungos, etc), e as condiçóes de higiene e segurança, bem como as características antropométricas dos postos de trabalho. Para Dejours, Abdoucheli e Jayet (1994), faz-se necessário considerar, além das condiçôes de trabalho, a dimensão organizacional que se constitui na divisão das tarefas, nas relações de produção, entre outros aspectos.

Barbosa e Soler (2003) citam que trabalhadoras de Enfermagem se submetem constantemente a condições inadequadas de trabalho, ocasionando licenças para tratamentos de saúde e acidentes de trabalho. A maioria das queixas de saúde nos trabalhadores de Enfermagem é relacionada ao sistema osteomuscular e às condiçóes na realização de procedimentos relativos à assistência de Enfermagem, como a higiene de pacientes, a arrumaçấo dos leitos, a realização de curativos, o transporte e a manipulação dos pacientes, entre outras, que podem contribuir para a gênese de um distúrbio osteomuscular (LEITE; SILVA; MERIGHI, 2007). Em relação às instituiçôes asilares, Silva et al. (2008) citam que estas muitas vezes não apresentam estrutura física adequada, além de disporem de número insuficiente de trabalhadores e apresentarem recursos materiais precários, entre outros problemas, tanto para os funcionários quanto para seus clientes, os idosos.

O objetivo deste estudo foi investigar os aspectos de risco para os distúrbios osteomusculares de trabalhadores de enfermagem que cuidavam/assistiam idosos em uma instituição asilar na cidade de Santos-SP.

\section{Materiais e métodos}

Este estudo é exploratório, descritivo e recorte de um estudo maior, realizado em duas Instituiçôes de Longa Permanência de Idosos, na cidade de Santos-SP. Inicialmente, realizou-se a seleção aleatória de Instituiçôes Asilares, sendo este estudo realizado em uma instituição filantrópica. Foram selecionados trabalhadores, tendo como critério de seleção o fato de atuarem junto aos idosos em atividades de trabalho (banho, troca de fraldas, entre outras).
Organizou-se instrumental que reuniu dados demográficos (idade, gênero, escolaridade), perguntas relacionadas ao trabalho, como: tempo de serviço, horas trabalhadas/dia/semana, tarefas percebidas como de maior dificuldade (quanto ao esforço físico), entre outras. Esse instrumental foi aplicado por meio de entrevistas e aplicou-se também o Questionário Nórdico de Sintomas Osteomusculares - QNSO (PINHEIRO; TRÓCCOLI; CARVEL, 2002), com questões adicionais, incluindo sintomas nos 30 dias anteriores à aplicação do questionário. Como complemento, foram selecionados idosos assistidos-cuidados diariamente pelos mesmos trabalhadores nas tarefas de trabalho percebidas como de maior dificuldade, para aplicação do Índice de Barthel (MAHONEY; BARTHEL, 1965). Em caso de não obtenção de dados por parte dos idosos, os trabalhadores respondiam por eles.

Posteriormente, realizou-se levantamento das tarefas e observaçôes sistemáticas das atividades de trabalho dos trabalhadores da equipe de Enfermagem, exceto enfermeiros, com sintomas osteomusculares nos 30 dias anteriores, e com base na Ergonomia (GUÉRIN et al., 1997). As observaçôes sistemáticas têm o objetivo de investigar aspectos ou variáveis pré-definidas por meio de formulação de hipóteses. Foram selecionadas para as observaçóes, as tarefas: transferências e movimentaçóes dos idosos, dar o banho e a troca de fraldas. Essas tarefas foram selecionadas por serem as tarefas percebidas como de maior dificuldade (dado obtido por meio de questáo em instrumental inicial aplicado sob forma de entrevista). O estudo foi realizado nessa instituiçáo durante um período de 2,5 meses, com tempo médio de duas horas, duas vezes por semana. Foram utilizados papel e caneta para registros de falas dos trabalhadores durante as atividades de trabalho.

O projeto foi aprovado pelo Comitê de Ética em Pesquisa da Universidade Federal de São Paulo (CEP: 0310/09).

\section{Resultados e discussão}

\subsection{Instituição: a quem se destina, espaço físico e recursos humanos}

A Instituição de Longa Permanência para Idosos deste estudo contava com 48 idosos no total, sendo que 40 idosos (20 do gênero feminino e 20 do gênero masculino) eram cuidados-assistidos diariamente pelos trabalhadores de Enfermagem nas tarefas selecionadas para as observaçóes; os demais idosos eram totalmente independentes. A equipe 
de Enfermagem era composta por 9 trabalhadores (enfermeiro, técnicos e auxiliares de Enfermagem), sendo que, atuavam diretamente junto aos 40 idosos, 08 trabalhadores (07 do gênero feminino e 01 do gênero masculino). A enfermeira chefe não integrou as análises deste estudo por não atuar diretamente junto aos idosos nas tarefas selecionadas para as observaçóes. A Instituição contava ainda com psicólogo e assistente social, e dava a prioridade de entrada na instituição aos idosos que não possuíam família e/ou a família não apresentava condiçóes para manter o seu cuidado.

Em relação ao espaço físico, a Instituição apresentava dois setores, o masculino e o feminino. Em cada setor, havia um banheiro grande com mais de um chuveiro e vasos sanitários, uma sala de televisão, ao lado dos quartos, e camas distribuídas pelos quartos; havia também um refeitório e um pátio compartilhados por todos os idosos de ambos os gêneros. As portas de alguns quartos davam para o pátio, onde havia algumas plantas e cadeiras de jardim; ainda no pátio, havia um caminho a percorrer até o refeitório com cháo em cimento, alguns degraus e rampas.

Os trabalhadores da área de Enfermagem tinham duas salas, sendo uma da enfermeira chefe e outra de uso coletivo, com um banheiro, cozinha com pia, geladeira e bancadas para armazenamento de determinados medicamentos, soros, etc.

Os turnos de trabalho dos trabalhadores (exceto enfermeiro) aconteciam de modo geral no esquema de $12 \times 36$ horas (trabalhavam um dia e folgavam no dia seguinte), e em turnos diurno e noturno, de segunda a segunda. Embora o número total de trabalhadores que cuidavam/assistiam os idosos diariamente fosse 08 , eles náo trabalhavam todos juntos nos mesmos turnos e dias. Nos períodos da manhã e da tarde, permaneciam de 02 a 03 trabalhadores, que se dividiam entre dois setores da instituição (masculino e feminino), e no período noturno, apenas 01 trabalhador.

\subsection{Dados demográficos gerais, de profissão, tempo de serviço e número dos idosos assistidos}

Os dados demográficos gerais dos trabalhadores, de profissão registrada, tempo de serviço e número de idosos cuidados/assistidos encontram-se na Tabela 1.

Na Tabela 1, o gênero feminino se destacou entre os trabalhadores, o que pode estar relacionado à própria profissão, fato discutido por Maffioletti, Loyola e Nigri (2006), que apontaram que o trabalho de quem cuida de idosos é desenvolvido, em sua maioria, por mulheres. Na Tabela 1, também se observou um tempo de serviço de alguns trabalhadores inferior a cinco anos de trabalho, sugerindo-se a existência de certa rotatividade no trabalho, o que pode indicar insatisfação.

\subsection{Os sintomas osteomusculares dos trabalhadores}

Do número total de trabalhadores que cuidavam/ assistiam os idosos $(\mathrm{n}=08), 07$ relataram dores osteomusculares nos 30 dias anteriores, sendo que 06 também relataram dores nos últimos 07 dias desse período. As regióes mais acometidas foram: região

Tabela 1. Dados demográficos gerais, de profissão, tempo de serviço (exceto enfermeiro) e número de idosos cuidados/assistidos da Instituição.

\begin{tabular}{ll}
\hline Quantidade de trabalhadores & \multicolumn{1}{c}{$\mathbf{N}=\mathbf{0 8}$} \\
Gênero & Feminino $\mathrm{n}=07$ \\
& Masculino $\mathrm{n}=01$ \\
Faixa etária & De 30 a 58 anos de idade \\
Escolaridade & Fundamental completo $\mathrm{n}=01$ \\
& Médio completo $\mathrm{n}=06$ \\
& Superior $\mathrm{n}=01$ \\
Profissão registrada & Técnicos de enfermagem $\mathrm{n}=06$ \\
& Auxiliares de enfermagem $\mathrm{n}=02$ \\
Tempo de serviço & Menos de 1 ano $\mathrm{n}=01$ \\
& 1 a 2 anos $\mathrm{n}=02$ \\
& 3 a 4 anos $\mathrm{n}=02$ \\
& 5 anos ou mais $\mathrm{n}=03$ \\
& $\mathrm{~N}=48$ \\
Quantidade de idosos & $\mathrm{N}=40$ \\
Quantidade de idosos diretamente cuidados/ & \\
assistidos/ dia pelos trabalhadores & \\
\hline
\end{tabular}


lombar $(\mathrm{n}=07)$, quadril/coxas $(\mathrm{n}=04)$, regiáo cervical $(\mathrm{n}=02)$, ombros $(\mathrm{n}=02)$ e tornozelos/pés $(\mathrm{n}=02)$, entre outras, havendo mais de uma região acometida em alguns trabalhadores. Estudos apontaram as regiôes de coluna lombar e ombros como sendo regiôes mais acometidas entre os trabalhadores de Enfermagem (MUROFUSE; MARZIALI, 2005; GURGUEIRA; ALEXANDRE; CORREA FILHO, 2003; PARADA; ALEXANDRE; BENATTI, 2002). Foi registrado nesse local um total de 02 afastamentos do trabalho nos 12 meses anteriores, sendo um deles por afecção osteomuscular.

\subsection{Níveis de capacidade funcional dos idosos}

Em relaçáo à capacidade funcional dos idosos selecionados $(n=40), 40,0 \%(n=16)$ apresentaram dependência total, 7,5\% $(\mathrm{n}=3)$ dependência grave, $17,5 \%(\mathrm{n}=7)$ dependência moderada e 35,0\% $(\mathrm{n}=14)$ dependência leve, havendo supostamente exigências de maior esforço físico no cuidado/ assistência aos idosos com maiores dependências, $65,0 \%(n=26)$. Um dos grandes problemas do processo de envelhecimento humano está associado à perda da capacidade funcional que, segundo a Organização... (2003), é um qualificador que indica o nível máximo possível de funcionalidade que uma pessoa pode atingir, ajustada para o ambiente. Essa possível perda da capacidade funcional contribui para o quadro de dependência do idoso, afetando sua autonomia e sua qualidade de vida, favorecendo a necessidade de cuidados de profissionais. Silva et al. (2008) relataram que cuidar de idosos institucionalizados não é uma tarefa fácil, principalmente daqueles que apresentam demências ou dependências graves.

\subsection{As tarefas e atividades de trabalho}

De um modo geral, as principais tarefas dos trabalhadores (exceto enfermeiro) no período da manhã eram: dar e/ou supervisionar o banho dos idosos, incluindo vestimenta e higiene pessoal dos mesmos (como, por exemplo, escovar os dentes), preparar e dar as medicaçôes, arrumar as camas dos idosos, servir o café da manhã, trocar as fraldas, servir o almoço, entre outras. No período da tarde, as tarefas eram: preparar e dar as medicaçôes aos idosos, servir o lanche da tarde, trocar as fraldas, servir o jantar (no final da tarde), eventualmente acompanhar os idosos em horários de visitas, entre outras. Já no período da noite, eram: preparar e dar a medicaçáo aos idosos, servir o lanche da noite, trocar as fraldas e realizar uma ronda noturna pelos dois setores, entre outras. Ocasionalmente, também verificavam a pressão arterial sistêmica $(\mathrm{PA})$ e os níveis de glicemia.

Nessa instituição, os trabalhadores se dividiam nas tarefas de trabalho com base nos dois setores $\mathrm{da}$ instituição. As tarefas selecionadas para as observaçóes sistemáticas foram: transferências e deslocamentos dos idosos, dar banho e a troca de fraldas.

\subsubsection{As transferências e os deslocamentos}

As transferências observadas referiram-se às transferências posturais dos idosos da cama para a cadeira de rodas, da cadeira de rodas para a cadeira de banho e desta, novamente, para a cama e/ou cadeira de rodas, sendo realizadas com maior frequência pelos trabalhadores no período diurno. Já os deslocamentos (ou movimentaçôes) caracterizavam-se por deslocar manualmente os idosos que utilizavam as cadeiras de rodas para os diversos locais da instituição, como refeitório, quartos, sala de televisão, entre outros; os deslocamentos eram realizados também durante os três períodos de trabalho, sendo mais evidentes nos períodos da manhã e da tarde.

No período da manhã, antes de dar o banho nos idosos, os trabalhadores já levavam as cadeiras de banho que utilizariam para os quartos dos idosos e, em seguida, realizavam a primeira transferência do dia: retirar o idoso da cama e transferi-lo para a cadeira de banho, quando, logo em seguida, o levavam para o banheiro, onde seria realizado o banho. Em geral, as transferências eram realizadas por duas trabalhadoras no setor feminino e por um trabalhador no setor masculino, havendo situaçóes em que os trabalhadores realizavam a transferência sozinhos, gerando sobrecargas especialmente físicas.

A repetitividade de tarefas aliada ao peso de alguns idosos foram aspectos de risco para surgirem os sintomas osteomusculares nas transferências posturais, como observado na fala de uma trabalhadora: "o pior mesmo éo peso, pegar da cama, pôr na cadeira de banho, tirar da cadeira de banho..." e, em outra fala de outro trabalhador: "tem morador que pesa 100 kilos... ai eu sinto muita dor na coluna..". Gurgueira, Alexandre e Correa Filho (2003) também evidenciaram o sobrepeso de pacientes como um aspecto de risco para dores osteomusculares entre trabalhadores de Enfermagem. Neste estudo, foi constatado que a repetitividade e o fato de realizarem sozinhos algumas tarefas junto aos idosos com sobrepeso ou obesos foram aspectos agravantes para o surgimento de sintomas osteomusculares. 
Logo após o banho, outra transferência era realizada: transferir o idoso da cadeira de banho para a cadeira de rodas, ainda dentro do banheiro. Após essa transferência, os trabalhadores executavam as tarefas de higiene pessoal dos idosos e vestimenta, para, em seguida, deslocá-los até o pátio, onde ficavam aguardando o horário do almoço. Os idosos que tomavam banho primeiramente eram levados até o pátio e aguardavam os demais, para, então, serem levados até o refeitório. O caminho até o refeitório era grande, com alguns pequenos degraus e rampas, e normalmente os trabalhadores deslocavam os idosos com sobrepesos ou obesos em cadeiras de rodas, que nem sempre estavam em condições satisfatórias, ocasionando desgaste.

O ritmo do trabalho nesse período era acelerado, pois os trabalhadores tinham de deslocar todos os idosos para o refeitório. No período da tarde, eram realizadas outras transferências: transferir os idosos da cadeira de rodas para a cama e transferi-los da cama para a cadeira de rodas, quando já acordados; dois trabalhadores se dividiam nesse período entre os setores feminino e masculino. No período da noite, as transferências eram realizadas antes da troca de fraldas, quando os idosos iam dormir, sendo realizada pelo trabalhador plantonista. Além disso, outras transferências e outros deslocamentos ocorriam conforme solicitações dos idosos, havendo repetitividade e exigências físicas. Em muitos momentos, constatou-se o número insuficiente de trabalhadores para as demandas, como na fala: " $a$ gente aqui tem que fazer muitas coisas porque são poucos funcionários, a gente tem que fazer um esforço físico muito grande..."

Observaram-se sobrecargas físicas, especialmente junto aos idosos dependentes físico-funcionalmente. O espaço físico também contribuiu para o cansaço, como observado na fala dessa trabalhadora: "aqui como é grande, você anda muito, então você cansa demais...". A repetitividade em deslocamentos foi um fator que influenciou nos sintomas, como nessa fala de outra trabalhadora: "a gente tem que levar pra lá... pra cá... traz e leva... dá uma dorzinha”. É importante lembrar que, conforme as observaçóes, as exigências físicas não eram somente nos deslocamentos, pois estas se acumulavam ao longo do dia; além disso, os idosos também solicitavam outras tarefas. Os trabalhadores acabavam se sujeitando às condiçóes e exigências impostas no trabalho por várias razôes, entre as quais a garantia de emprego; e trabalhavam, muitas vezes, suportando sintomas osteomusculares que, segundo Alencar e Montrezor (2010), pareciam ser "banalizados".

\subsubsection{O banho}

Quanto ao banho, primeiramente os trabalhadores colocavam os equipamentos de proteção e higiene necessários, que eram: avental, botas, toca de cabelo, óculos, luva e máscara; quanto aos materiais de uso (xampu, condicionador, sabonete, escova e pasta de dente, entre outros) de cada idoso, estes já se encontravam no banheiro, bem como as roupas limpas de vestir (tarefas executadas pelo trabalhador do setor de limpeza). Assim que o idoso chegava ao banheiro trazido pelo trabalhador na cadeira de banho, era testada a água do chuveiro, deixando-a em temperatura morna e, logo depois, com a utilização de uma ducha de banho manual, os trabalhadores molhavam os idosos, e pegavam o sabonete. Este, algumas vezes, estava em local alto, necessitando, para alguns trabalhadores, se colocar nas pontas dos pés e havendo, assim, exigências de máximos alcances articulares. Posteriormente, passavam o sabonete com a ducha de banho no corpo e lavavam a cabeça com xampu, entre outros produtos afins.

O trabalhador, em determinados momentos, está sujeito ao desgaste físico e mental, necessitando de paciência e compreensão frente aos diferentes estados emocionais dos idosos, uma vez que estes podem também apresentar demência, transtornos mentais ou estarem irritados, agressivos, entre outras manifestaçóes. Sob o aspecto físico, durante esses procedimentos, os trabalhadores permaneciam grande parte do tempo na frente do idoso com flexão de tronco e de joelhos (permanecendo, em geral, semifletidos), podendo ser uma postura de risco para lombalgias, pelo grau observado de flexão de tronco e repetitividade.

O banho, em geral, era realizado por duas trabalhadoras no setor feminino, com ritmo acelerado; enquanto uma delas estava dando o banho, a outra trabalhadora já estava enxugando outra idosa: enxugava, passava talco e desodorante (alguns produtos eram obtidos por doaçóes), para logo em seguida começarem a vestir as idosas. Após o banho, também era realizada a escovaçáo dos dentes, nem sempre com tempo suficiente para a realização "adequada". No setor masculino, as tarefas relacionadas a dar banho eram realizadas por um único trabalhador do gênero masculino, seguindo os mesmos procedimentos gerais descritos, e realizando também as atividades de higiene pessoal e vestimenta de cada idoso. Havia maiores sobrecargas físicas para esse trabalhador por ele estar sempre sozinho: ele dava o banho em cerca de 13 idosos/ dia que apresentavam dependências funcionais supostamente relevantes, havendo nesse caso maiores 
exigências físicas. Em função do ritmo e da pressão junto aos horários determinados, o trabalhador executava em geral os movimentos "com pressa" e sem "cuidados" posturais. As exigências foram observadas tanto nas transferências posturais, nos deslocamentos até o banheiro, quanto no ato de dar o banho propriamente dito; apesar de o trabalhador ser do gênero masculino e haver diferenças de forças musculares entre homens e mulheres, os idosos também eram do gênero masculino e supostamente maiores (em estatura) do que as mulheres idosas. Houve também situaçóes em que, na ausência de trabalhadora no setor feminino (por exemplo, falta no dia), o trabalhador do setor masculino era requisitado para ajudar, o mesmo acontecendo quando o trabalhador (homem) do setor masculino não estava trabalhando, gerando sobrecargas e desgaste muitas vezes pela falta de pessoal suficiente, entre outras situaçôes. $\mathrm{O}$ fato de haver poucos trabalhadores para as tarefas foi observado na fala do trabalhador: "eu faço tudo sozinho... já tô sentindo dor nos braços.”, ou seja, influenciando nos sintomas osteomusculares.

Durante as observaçóes, havia alguns idosos que não conseguiam colaborar com os trabalhadores na execução de alguns movimentos ou em determinados procedimentos, e outros que até poderiam, entretanto não eram muitas vezes estimulados pelos trabalhadores, possivelmente por causa do ritmo acelerado de trabalho no período matutino. $\mathrm{O}$ não estímulo junto aos idosos pode ser observado na fala do trabalhador: "a gente já pega, já vira... para não ter que esperar". O fato de não serem estimulados ao longo do tempo pode influenciar no agravamento das condiçóes de saúde.

Nas observações, foram evidentes posturas e movimentos de risco especialmente para as lombalgias, com flexão de tronco e joelhos (ora fletidos, ora estendidos). Em relaçáo à postura corporal adotada pelos trabalhadores de Enfermagem durante as atividades de trabalho, Zanon e Marziale (2000) constataram que a postura corporal mais frequentemente adotada foi a coluna inclinada e as pernas em extensão de joelhos.

\subsubsection{A troca de fraldas}

As trocas de fraldas eram realizadas pelos trabalhadores nos três períodos. No período matutino, era realizada em geral por duas trabalhadoras, que se dividiam no setor feminino, e por um trabalhador no setor masculino; assim, os trabalhadores, após o banho, já colocavam a fralda no idoso. Para a realização das trocas, os idosos se apoiavam em uma barra de metal presa na parede do banheiro e o trabalhador trocava a fralda, permanecendo atrás do idoso, em geral com flexão de tronco e em um espaço físico pequeno, exigindo "ajustes" com posturas e movimentos muitas vezes inadequados.

Já no período da tarde, as trocas eram realizadas logo após o "descanso" dos idosos. Muitas vezes, quando os idosos apresentavam um grau de comprometimento funcional (físico) "elevado", eram necessários dois trabalhadores para conseguirem trocar a fralda. Em geral, os trabalhadores colocavam os idosos de lado na cama (decúbito lateral), trazendo-os para a beirada da cama (ficando mais próximos dos trabalhadores), afastavam suas roupas e tiravam a fralda usada, colocavam a fralda na cama e trocavam posicionando o idoso sobre a fralda, náo havendo a necessidade de colocá-los em pé e/ou sentados. Os trabalhadores realizavam essas tarefas na posição em pé (ortostática) e também com flexão de tronco, sendo que, em algumas situaçôes, alguns idosos permaneciam dormindo, aumentando as exigências físicas.

As camas da Instituição não tinham alturas iguais, umas eram baixas para os idosos não caírem e outras eram camas hospitalares (mais altas); ambas as alturas geravam algumas situaçóes dificultosas para o trabalhador nas execuçôes das trocas de fraldas, como na fala: "tem que fazer muito esforço... a cama é muito alta!".

Havia também um ritmo acelerado de trabalho, pois, logo após a troca das fraldas, os trabalhadores tinham que preparar e dar a medicação, e também servir o lanche (às vezes no refeitório, às vezes no pátio). Havia sobrecargas de trabalho pelo número de idosos, como na fala de outra trabalhadora: "são muitos (idosos)... nos dois setores". A sobrecarga de trabalho e o pouco tempo destinado ao descanso são situaçóes que comprometem a saúde mental do trabalhador de Enfermagem, podendo acarretar problemas pessoais, nas relaçôes interpessoais e no desempenho de suas atividades profissionais (SILVA; YAMADA, 2008).

Havia uma relação com a chefia administrativa considerada por alguns trabalhadores como "complicada", por esta não compreender as necessidades dos trabalhadores, não promover um espaço de escuta quanto às queixas dos trabalhadores, entre outras lacunas, que podem gerar desgaste.

Há relaçôes entre aspectos estressores e os distúrbios osteomusculares relacionados ao trabalho. Bongers et al. (1993) citam que a pressão do tempo aumenta a ocorrência de aceleração dos movimentos e de posturas inadequadas, e o estresse pode elevar a intensidade da contração muscular e, a longo 
prazo, exacerbar os sintomas, sendo que também os fatores psicossociais podem influenciar. Segundo Pinheiro, Tróccoli e Paz (2006), fatores psicossociais ocupacionais descrevem como a organização do trabalho é percebida pelos trabalhadores. Apesar de não ser objeto de estudo da Ergonomia, essa ciência pode contribuir também com análises de situaçôes que podem gerar desgaste relacionado às cargas afetivas.

Na referida instituição, em função principalmente do número reduzido de trabalhadores para a quantidade de idosos que necessitavam de cuidado/ assistência e do ritmo de trabalho acelerado para o banho e a troca de fraldas, os trabalhadores não apresentavam uma divisão de tarefas satisfatória para todos, e todos os trabalhadores tentavam "dar conta" de todas as demandas.

Alguns aspectos de risco para os distúrbios osteomusculares foram identificados: a altura das camas, a distância entre os locais, as condiçôes das cadeiras de rodas, a repetitividade dos movimentos e as posturas inadequadas, o ritmo acelerado de trabalho, a capacidade funcional dos idosos, entre outros.

Ao final do estudo, foram apresentados os dados levantados, discutidos e validados junto aos trabalhadores, que concordaram com os problemas identificados e elaboraram sugestôes de melhorias. Posteriormente, foi elaborado um relatório final com os dados do estudo, incluindo as sugestóes propostas, que foi apresentado e entregue ao gestor. Algumas das recomendaçóes foram: melhorias das cadeiras de rodas e do trajeto externo (degraus e rampas); adequaçóes das alturas das barras de metal no banheiro; evitar a realização de transferências e deslocamentos de idosos pesados ou de grande dependência funcional de modo isolado (sozinho); incluir pequeno intervalo/pausa durante o trabalho (além do almoço); melhorar as divisões de tarefas; aumentar o número de trabalhadores (pelo menos nos lugares dos dois trabalhadores afastados); promover reuniôes de equipe, com abertura para discussóes sobre dificuldades relacionadas ao trabalho, entre outras sugestôes.

A Terapia Ocupacional, na análise da atividade, considera os aspectos afetivos relacionados com sua realização, que podem ser verbalizados e/ou expressos pelos trabalhadores de diferentes formas (WATANABE; GONÇALVEZ, 2004). Por isso e por outras habilidades profissionais do terapeuta ocupacional, e pelas circunstâncias de possível desgaste evidenciadas neste estudo, é indicado, além de acompanhamento durante o processo de implementação de melhorias nas condições de trabalho, um trabalho em grupo terapêutico e com realização de atividades expressivas (por exemplo, jogos temáticos reflexivos, dinâmicas corporais, entre outras). É muito importante que esse trabalho seja coordenado por terapeuta ocupacional que atue na área de Saúde e Trabalho, para que possam ser explorados os aspectos de desgaste junto aos trabalhadores e a consciência corporal, entre outros. As questôes que envolvem os distúrbios osteomusculares são complexas e compreendem dimensôes psicossociais e organizacionais do trabalho, além das questóes biomecânicas, que precisam ser levadas em consideração. Intervenções interdisciplinares são também indicadas. Ressaltou-se também a importância de estímulos junto aos idosos, para se evitarem agravos à saúde (física e mental) dos mesmos.

\section{Considerações finais}

Foram identificados alguns riscos para os distúrbios osteomusculares, como o peso dos idosos, a disposição dos ambientes de trabalho (entre os espaços que compóem a instituiçáo), as condiçóes das cadeiras de rodas, a altura de camas, a repetitividade dos movimentos e a execução de posturas inadequadas, aliados aos níveis de capacidade funcional dos idosos, que contribuíram para o surgimento de sintomas osteomusculares entre os trabalhadores.

Alguns aspectos da organização do trabalho também influenciaram nos sintomas osteomusculares dos trabalhadores, como: ritmo de trabalho acelerado, número insuficiente de trabalhadores, pressão temporal e distribuição inadequada de tarefas por trabalhador, podendo gerar desgaste físico e mental.

Pesquisas futuras devem investigar e aprofundar as relações entre os distúrbios osteomusculares relacionados ao trabalho e as condições de trabalho em instituições de idosos, levando-se em conta também aspectos da organização do trabalho, com o intuito de contribuir para a prevenção desses distúrbios.

\section{Referências}

ALENCAR, M. C. B.; MONTREZOR, J. B. Aspectos da Organização do Trabalho e os distúrbios osteomusculares: um estudo com trabalhadores em instituições de Longa Permanência de Idosos. Revista de Terapia Ocupacional da USP, v. 21, n. 1, p. 15-22, 2010.

ALEXANDRE, N. M. C. Ergonomia e as atividades ocupacionais da equipe de enfermagem. Revista Escola de Enfermagem da USP, v. 32, n. 01, p. 84-90, 1998. http://dx.doi.org/10.1590/S0080-62341998000100013 
BARBOSA, D. B.; SOLER, Z. A. S. G. Afastamentos do trabalho na enfermagem: ocorrências com trabalhadores de um hospital de ensino. Revista da Escola de Enfermagem - USP, v. 11, n. 2, p. 177-183, 2003. PMid:12852294. http://dx.doi.org/10.1590/ S0104-11692003000200006

BONGERS, P. M.; WINTER, C. R.; KOMPIER, M. A. J.; ILDEBRANDT, V. H. Psychosocial factors at work and musculoskeletal disease. Scandinavian Journal of Work Environment Health, v. 19, p. 297-312, 1993.

BRASIL. Ministério da Saúde. Representação no Brasil da OPAS/OMS. Doenças relacionadas ao trabalho: manual de procedimentos para os serviços da saúde. Brasília, 2001.

BRASIL. Ministério da Saúde. Secretaria de Atenção à Saúde. Lesões por Esforços Repetitivos (LER) Distúrbios Osteomusculares Relacionados ao Trabalho (DORT). Brasília: Departamento de Açóes Programáticas Estratégicas, 2006.

BRITO, J. C. Procurando compreender os conceitos de carga, trabalho e risco (tecnológico). Revista Brasileira de Saúde Ocupacional, v. 19, n. 72, p. 38-39, 1991.

CHIAVEGATO FILHO, L. G.; PEREIRA JUNIOR, A. Work related musculoskeletal diseases: multifactorial etiology and explanatory models. Interface - Comunicação, Saúde, Educação, v. 08, n. 14, p. 149-162, 2004.

DANIELLOU, F. (Org). A ergonomia em busca de seus princípios: debates epistemológicos. São Paulo: Ed. Edgard Blucher, 2004.

DEJOURS, C.; ABDOUCHELI, E.; JAYET, C. Psicodinâmica do trabalho: contribuiçốes da escola dejouriana a análise da relação prazer, sofrimento e trabalho. Atlas: São Paulo, 1994.

DEJOURS, C. A loucura do trabalho. São Paulo: Cortez, 1992.

DEJOURS, C. O fator humano. Rio de Janeiro: FGV, 2005. p. $40-42$

FALZON, P. Ergonomia. São Paulo: Ed. Blucher, 2007.

GUÉRIN, F.; LAVILLE, A.; DANIELLOU, F.; DURAFFOUG, J.; KERGUELEN, A. Compreender o trabalho para transformá-lo: a prática da Ergonomia. São Paulo: Ed. Edgard Blucher Ltda, 1997.

GURGUEIRA, G. P.; ALEXANDRE, N. M. C.; CORREA FILHO, H. P. Prevalência de sintomas músculo-esqueléticos em trabalhadores de enfermagem. Revista Latino-Americana de Enfermagem, v. 11, n. 5, p. 608-613, 2003. PMid:14978564. http://dx.doi. org/10.1590/S0104-11692003000500007

LANCMAN, S. Construção de novas teorias e práticas em Terapia Ocupacional, Saúde e trabalho. In: LANCMAN, S. (Org). Saúde, Trabalho e Terapia Ocupacional. São Paulo: Ed. Roca, 2004.

LEITE, P. C.; SILVA, A.; MERIGHI, A. B. A mulher trabalhadora de enfermagem e os distúrbios osteomusculares relacionados ao trabalho. Revista da
Escola de Enfermagem - USP, v. 41, n. 2, p. 287-291, 2007. http://dx.doi.org/10.1590/S0080-62342007000200016

MAFFIOLETTI, v. L. R.; LOYOLA, C. M. D.; NIGRI, F. N. Os sentidos e destinos do cuidar na preparaçáo dos cuidadores de idosos. Revista Ciência Saúde Coletiva, v. 11, n. 4, p. 1085-1092, 2006.

MAHONEY, F. I.; BARTHEL, D. Functional Evaluation: the Barthel Index. Maryland State Journal, v. 14, p. 56-61, 1965.

MUROFUSE, N. T.; MARZIALE, M. H. P. Doença do sistema osteomuscular em trabalhadores de enfermagem. Revista Latino-Americana de Enfermagem, v. 13, n. 03, p. 364-373, 2005. http://dx.doi. org/10.1590/S0104-11692005000300011

ORGANIZAÇÃO MUNDIAL DA SAÚDE - OMS. CIF - Classificação Internacional de Funcionalidade, Incapacidade e Saúde. Direção Geral da Saúde, 2003. D. Classificação detalhada com definiçốes.

PARADA, E. O.; ALEXANDRE, N. M. C.; BENATTI, M. C. C. Lesões ocupacionais afetando a coluna vertebral em trabalhadores de enfermagem. Revista Latino-Americana de Enfermagem, v. 10, n. 01, p. 64-69, 2002. http:// dx.doi.org/10.1590/S0104-11692002000100010

PINHEIRO, F. A.; TRÓCCOLI, B. T.; CARVEL, C. V. Validação do questionário de sintomas osteomusculares como medida de morbidade. Revista de Saúde Pública, v. 36, p. 307-312, 2002. http://dx.doi.org/10.1590/ S0034-89102002000300008

PINHEIRO, F. A.; TRÓCCOLI, B. T; PAZ, M. G. T. Preditores psicossociais de sintomas osteomusculares: a importância das relaçóes de mediação e moderação. Psicologia: Reflexão \&Crítica, v. 19, n. 1, p. 142-150, 2006. http://dx.doi.org/10.1590/ S0102-79722006000100019

PUNNET, L.; WEGMAN, D. H. Work related musculoskeletal disorder: the epidemiologic evidence and debate. Journal of Eletromyography and Kinesiology, v. 14, p. 13-24, 2004. PMid:14759746. http://dx.doi. org/10.1016/j.jelekin.2003.09.015

SILVA, L. G.; BARLEM, E. L. D.; LUNARDI, v. L.; SANTOS, S. S. C. Educação permanente: instrumento de trabalho do enfermeiro em instituição de longa permanência. Revista Ciência, Cuidado e Saúde, v. 7, n. 2, p. 256-261, 2008.

SILVA, L. G.; YAMADA, K. N. Estresse ocupacional em trabalhadores de uma unidade de internação de um hospital escola. Revista Ciência, Cuidado e Saúde, v. 7, n. 2, p. 98-105, 2008.

WATANABE, M.; GONÇALVES, R. M. A. Relações conceituais entre Terapia Ocupacional e Ergonomia. In: LANCMAN, S (Org). Saúde, Trabalho e Terapia Ocupacional. São Paulo: Ed. Roca, 2004.

ZANON, E.; MARZIALE, M. H. P. Avaliação da postura corporal dos trabalhadores de enfermagem na movimentação de pacientes acamados. Revista Escola de Enfermagem da USP, v. 34, n. 01, p. 26-36, 2000. 


\section{Autores}

\section{Janaína Bussola Montrezor}

Formanda do curso de Terapia Ocupacional da Universidade Federal de São Paulo - UNIFESP, bolsista PIBIC/CNPq, São Paulo, SP, Brasil

\section{Maria do Carmo Baracho de Alencar}

Professora Doutora do Departamento de Ciências da Saúde da Universidade Federal de Sáo Paulo UNIFESP, Santos, SP, Brasil

\section{Contribuição dos Autores}

Janaina Bussola Montrezor participou do projeto, da obtenção, análise e discussão dos dados, além da elaboração e revisão do manuscrito. Maria do Carmo Baracho de Alencar coordenou e orientou a pesquisa, participando da análise, discussão e interpretação dos dados, além da elaboração e revisáo do manuscrito. 